\title{
Starting out in teaching: \\ Surviving or thriving as a new teacher
}

\author{
Marie Cameron, Susan Lovett, and Jennifer Garvey Berger
}

\begin{abstract}
The first day was scary because you turn up and you see all these smiling faces and the odd parent who has come to see. You look around and there is no associate teacher to call backup on. You're it and that's when it hit home because coming in early and setting the class up, that was all cool, but then they were all sitting there looking at you saying 'Right teach us!' You're going 'It's me now!' (Robert, 26-30, intermediate school teacher)
\end{abstract}

Starting out in teaching is indeed "scary" for most new teachers (Roehrig, Pressley, \& Talotta, 2002). As is well known, new teachers assume similar responsibilities to those who have been teaching for years, and they have to get up to speed quickly (Stansbury \& Zimmerman, 2002). Too often they are thrown in at the deep end, and while they may survive to teach another day, their dropout rate is worrying, as are the lessons they are learning about teaching. As Bubb (2007, p. 1) notes, "The first year is the most formative period in a teacher's career and support is crucial if they are to develop the competencies, confidence and attitudes that will keep them happy and successful in the job." New teacher attrition causes concern in many jurisdictions (OECD, 2005), and despite comparatively generous funding for induction in New Zealand, attrition rates are broadly similar to those in the United States, Australia, and the United Kingdom, with around 37 percent of all new teachers leaving the teaching profession after three years (Elvidge, 2002). Teacher induction is now recognised as important, both in retaining beginning teachers and in establishing strong foundations for quality teaching
(Cochran-Smith, 2004; Ingersoll \& Kralik, 2004; Kelley, 2004; OECD, 2005; Youngs, 2002).

As part of a longitudinal study of New Zealand primary and secondary teachers, we were interested in what teachers in their third year of teaching recalled about their two-year period of induction to teaching. Earlier New Zealand research on induction (Dewar, Kennedy, Staig, \& Cox, 2003; Mansell, 1996; Renwick, 2001) indicated that not all new teachers were given adequate support, with primary teachers somewhat more likely to find themselves in supportive workplaces. The key purpose of this article is to highlight the practices that teachers in our NZCER study recalled as helping them to feel successful and positive about their work as teachers and as members of the teaching profession.

\section{Context of this study}

This article draws upon a larger study of a cohort of New Zealand teachers (Cameron, Baker, \& Lovett, 2006; Cameron, Berger, Lovett, \& Baker, 2007) that highlighted the early career experiences and conditions that not only keep teachers in teaching, but also assist them to develop their teaching practice and grow professionally. Unlike other studies of teacher induction, we have focused on a purposive sample of teachers who were identified as being of particular promise. The definition we used to identify our sample was "someone likely to make a significant contribution to teaching and to children's and young persons' learning, and the kind of person whom others hope will remain in teaching". We were interested in 
discovering what is needed to ensure that those teachers, who have the potential to be our very best teachers, are nurtured in ways which keep them in the profession, and which grow their expertise as teachers.

It was for this reason that in 2005 we began to track the experiences of a group of primary and secondary school teachers from their third year of teaching (2005-2008), using data from interviews, surveys, and workshops. The teachers in our study were nominated by teacher educators from six initial teacher education programmes in five cities as meeting our definition of a teacher of promise. To be in the study, this nomination had to be supported by their principal or head of department in the school where these teachers were now employed. The final sample comprised 57 teachers. Mirroring the profession in general, there were more women than men in our sample, although 35 percent of the sample were male. Most of the teachers (63 percent) were under 30 years of age, although almost 20 percent were aged between 41-50 years. Most teachers were Pākehā and 12 percent were Māori. Around two-thirds of the teachers (almost all the male teachers and half the women) had worked in other employment before becoming teachers.

Relatively few of the teachers in our sample (16 percent) were teaching in low-decile schools, and 25 percent were teaching in highdecile schools. Twenty-five teachers taught in primary schools, 11 in intermediate schools, and 21 in secondary schools.

Despite their different backgrounds and school contexts, they all shared a desire to "make a difference to the world", which is why many had changed careers to make a difference by teaching, and why a fifth had changed schools after their first year if they did not feel successful in their first teaching position.

The information for this article was gathered in the first interview in 2005. As we analysed those interviews, we found that the teachers were describing three different kinds of induction experiences: supportive; unsupportive; or somewhat ad hoc induction. Our luckiest teachers worked in schools that supported them personally and with ongoing classroom-based pedagogical mentoring from a well-chosen tutor teacher. The unluckiest teachers (a quarter of the sample) were in schools that lacked commitment to supporting them to thrive and become successful teachers. They were left alone to work out how to teach, felt isolated in their schools or classrooms, or had colleagues who provided little emotional or teaching support. Bubb, Earley, and Totterdell (2005) describe the leaders in such schools as "rogue" leaders, who "treat new teachers unprofessionally, wasting public resources and, in some cases, hindering or potentially ruining individuals' careers and losing them to the teaching profession” (p. 255). The third group of teachers (20 percent) had friendly work environments, and felt able to ask their colleagues for help with specific problems, but they did not receive a classroom-based, structured induction programme that assisted them to develop their teaching.

For this article we have chosen to focus only on what schools did to assist beginning teachers to operate at levels beyond mere survival. We believe that those of you who are reading this article might have the possibility of making induction experiences better for the new teachers you work alongside. Thus we see particular value in naming induction strategies which might enable beginning teachers to realise their dreams to "make a difference" to children's and young persons' learning and lives.

\section{Induction experiences that make a difference for teachers of promise}

We have found that there are three major categories of teacher induction experiences that our teachers identified as most important: leadership and organisational commitment and practices; collegial support; and opportunities to continue learning about teaching. Each of these is explained below.

Alongside these factors, our study has highlighted the experiences and differences of beginning teachers working in primary, intermediate, and secondary schools. Threequarters of the primary school teachers, compared with a third of the intermediate and secondary teachers, worked in the most supportive schools. Conversely, about 25 percent of all teachers and almost half of the secondary teachers worked in the least supportive schools. We hope that by highlighting the specific attributes of these most supportive schools, we might increase the number of teachers who have these experiences. We start with the differences that leaders can make.

\section{Leadership and organisational commitment and practices}

Mulford (2003) considers that principals are the key to enhancing schools' capabilities to attract and retain teachers. While the principals in our study usually did not have a formal role in inducting beginning teachers, they influenced the environmental and organisational conditions that contributed to effective induction and the opportunities that teachers had to develop their teaching. Principals in supportive school contexts ensured that beginning teachers had guaranteed access to the allocated provisionally registered teacher (PRT) time allowance, ${ }^{1}$ protecting this time from other encroachments such as covering for teacher absences, or being the "kitchen manager".

Some schools had a policy of assigning smaller classes that were "easier to teach" to beginning teachers:

I have noticed the school, that they are very kind to the beginning teachers ... they will pick a class that is manageable so that the teacher can focus more on what they're doing rather than behaviour in the first year, and then gradually pick it up from there. (Barrie, 20-25, intermediate)

Secondary schools that kept the novice status of beginning teachers in mind restricted the numbers of different subjects and teaching levels, and ensured that they taught only subjects for which they were qualified.

The selection of tutor teacher was critical. It was important that the tutor teacher had the right mix of personal, curriculum knowledge, and teaching skills to work with a novice teacher. Other helpful organisational practices included ensuring that class timetabling allowed some time when both tutor teachers and beginning teachers were able to meet together and locating the beginning teacher's classroom near to their tutor teacher.

Principals also made it clear to beginning teachers that they were not expected to take on other roles in addition to their teaching. For example, Morag's principal told her:

Look, your responsibility in your first couple of years is to your class, and getting things up and running, getting your head around how to do things ... so don't feel guilty about the fact that you're not doing this, that and the next thing. (Morag, 26-30, primary)

Beginning teachers were also encouraged to use some of their PRT time to learn about their specific school and community contexts, a practice recommended by Feiman-Nemser (2001). Angela told us:

In my 0.2 time it was a good time to locate resources ... because they are sometimes hard to find. And so that was a focus for my first two terms, getting to know what's in the school, how to use it, getting all my planning right, finding other good resources for units... . Also 
I went and visited all the classrooms at different times, looking at the maths... I also went outside the school to get to know the National Library and get to know other things in our community.

(Angela, 31-40, intermediate)

There was also a clear set of experiences created by colleagues-both collectively and also individually - that were most important to teachers. The novice teachers who thrived had colleagues who offered emotional, logistical, and teaching support as well as individual tutor teachers who provided in-depth classroom mentoring.

\section{Emotional support}

Hargreaves and Fullan (2000) emphasise that emotional support is one of the strongest needs of beginning teachers, and that it is easy to lose sight of the emotional dimensions of teaching. Stansbury and Zimmerman (2000, p. 4) emphasise:

At this emotionally challenging time, more experienced colleagues can play an important role, serving as a sounding board and assuring beginners that their experience is normal, offering sympathy and perspective, and providing advice to help reduce the inevitable stress. While this type of support does little to directly improve teaching performance, it does much to promote beginning teachers' personal and professional well-being and transmit the culture of teaching.

Teachers were better able to settle into teaching within an organisational climate that appreciated that "being a new teacher is hard" and where mistakes were normal and to be expected:

The principal was excellent, and said 'The first year is your year to make mistakes.' So she let me know that ... and that she was there for guidance as was my tutor teacher. She said that Year 2 is to consolidate and take on board more responsibility. (Angela, 31-40, primary)

Other principals emphasised the importance of new teachers taking care of their health. For example, Claudia's principal was described as "a real people person" who ensured that:

our needs come first and he was constantly reminding me to take care of myself, and I got really sick in my first year of course, and it was like 'Don't come back, don't feel as if you have to be here, don't be a martyr', sort of thing. (Claudia, 41-50, primary)

\section{Collegial cultures}

Departmental cultures in secondary schools and syndicate teams in primary schools strongly influenced the opportunities beginning teachers had to work with, and learn from their more experienced colleagues. Teachers joining collaborative work cultures had greater opportunities to talk about teaching with their colleagues, share planning and resources, examine students' work, and benefit from the collective expertise of their team members.

Teachers in both primary and secondary schools considered that their knowledge and practice were developed primarily through their interactions with other teachers. Morag described how all the teachers in her team took responsibility for her induction, and went out of their way to offer suggestions, ideas, and resources:

I really am lucky to be in the junior syndicate 'cause everybody looks after one another and it's just fantastic. I had a really good tutor teacher who I was able to go to but it wasn't just her, it was, you know, it was any of the teachers in the syndicate I could go to for help, so I didn't just solely rely on my tutor teacher for assistance. (Morag, 26-30, primary)

While collective approaches were more likely to occur in primary schools, secondary teachers also provided examples of ways in which colleagues supported their induction. Leah, who left her first school because of a lack of departmental support and leadership, described her current department as:

a really cohesive department who really look after each other and help each other out. There is a whole feeling of working together collaboratively here. Here you feel like the HOD really is working for you and working to help you and the whole department and thinking about how we work as a group and thinking about what we do as a department a lot. (Leah, 31-40, secondary)

Steven, who is now a head of department, appreciated his colleagues' open-door practices and willingness to respond to his requests for guidance until he felt sufficiently confident to "fly solo a bit more" in his second year:

I felt conscious in my first year of teaching actually, that I was asking for advice too much from senior colleagues. You know, it felt like every day I was knocking on someone's door at the end of the day and going in and asking a question or asking 'Did I do the right thing, how would you have approached this?' 'How could I do this?' 'Can you have a look at this thing I've prepared, do you think it's okay?'

(Steven, 26-30, secondary)

However, it was up to him to seek assistance, and he did not have the benefit of a planned induction programme or participation in collective approaches to planning, teaching, and assessment. Scott and Dinham (2003), in a study of teachers in Australia, New Zealand, England, and the United States, identified a relationship between teachers who work together on relevant learning-related tasks, and their satisfaction as teachers. Teachers in our study also reported that participation in joint tasks relevant to teaching and learning was a very helpful opportunity for professional learning during their induction period. The sharing of knowledge and expertise allowed for distributive leadership and the collective enhancement of practice. Team moderation of student assessment was perceived as another opportunity to build shared understandings of student learning by both primary and secondary teachers:

We do assessments together, like performances, and we always moderate things within the department such as compositions, and exams and tests and such. We're lucky 'cause it's a small department and we can always [meet] together. All of us have strengths in different areas and we're very different as people, but we're also quite close and they've always been very supportive, especially in the first year when I needed it the most. (Olivia, 20-25, secondary)

Haden, a secondary school history teacher, was fortunate to belong to a stable department with colleagues who were very willing to scaffold his teaching of a new topic:

This year is the first year I've taught Singapore history and a New Zealand option. I didn't do NZ history at university. I read quite a lot about it and I knew it, but there's a difference between me knowing it and teaching 7 th formers to know it. So [HOD] has been fantastic, [teacher] has been brilliant. The two of them have both taught it for donkey's years so helping with resources, telling me 'Don't teach year by year, make sure you go by what the themes are.' It's been great. If I was in a school where I was the only teacher of history I would be in real trouble. I would battle through it, but I did a hell of a lot better job this year because of them. (Haden, 26-30, secondary) 


\section{A skilled and committed mentor (tutor teacher)}

Johnson, Kardos, Kauffman, Liu, \& Donaldson (2004, p. 9) define a mentor's work with a new teacher as "focused on the central components of teaching: classroom instruction, curriculum and lesson planning, and classroom management". Street (2004, p. 8) reports Rogoff's (1991) view that mentoring is a jointly constructed activity where the expert (mentor) assists the novice by "providing guidance, feedback and explanation" which allows the novice to develop increasingly more expert ways of solving problems of practice. While teachers may bring personal qualities and skills to their roles (Vonk, 1994), other skills such as a strong content knowledge, an understanding of the learning needs of beginning teachers, and how to provide differentiated guidance to another teacher cannot be assumed to be part of classroom teachers' repertoires.

For beginning teachers in our study, both interpersonal and wider professional expertise contributed to helpful mentoring:

She was very honest with me $\ldots$ and I

think one of the biggest things is, she teaches the way I would like to teach... She would come and model [in my classroom], and then watch me, and I would go up to her class and watch. (Zoē, 20-25, primary)

Successful mentoring depended on strong mentoring relationships, and sensitivity to the developmental needs of the beginning teachers, including knowing when to intervene, when to offer assistance, and when to stand back:

[She gave me] a lot of help with planning; we'd do a lot of planning together, so we [both] knew where we were going. I had a Year 5 class; she had a Year 6 in the same syndicate.... We'd do all our goal setting, things like that, do it together, she was basically just there, and I always felt that she was there when I needed her and she always knew when I needed her too. Sometimes she could just tell by talking to me that 'Okay, you need a bit of help here.' (Holly, 20-25, primary)

Mentoring was enhanced when tutor teachers' own commitments allowed them to spend "quality time" with their beginning teacher. This was more likely to occur when the tutor teacher did not have full-time classroom teaching responsibilities:

I had a tutor teacher, an amazing tutor teacher, and she was the reading recovery teacher for that school which freed her up to spend quite a lot of time with me... .
She spent a lot of time observing me... and a lot of time teaching with me. So I always felt there was someone I could go to, to ask questions; we basically wrote a programme ourselves that involved a lot of goal-setting on my part, observations, reflections, getting feedback from the children. I used to do that quite a lot and I'd basically have a piece of paper that I would write anything on there that I needed to talk to, about, either at the end of the day or at the end of the week and would look at those and look at how we could solve those problems in the next week. (Rose, 31-40, primary)

Tutor teachers also protected the new teachers from overworking, doing things to make their job easier and emphasising that teaching is a job that has no obvious end point:

She also very quickly discouraged me from putting in too many hours. When I first started I was working from 7.30 in the morning till maybe 6 at night and one day on the weekend I'd be out here and she said to me, 'Claudia you could do this job 24 hours a day, 7 days a week and you still wouldn't be finished so don't do it', and in the second term I got a bit more realistic. (Claudia, 41-50, primary)

\section{Ongoing learning about teaching}

One of the things teachers needed most was a way for them to hold on to their continued learning about teaching. They found this most in their opportunities to observe others and have conversations about teaching, and in their participating in wider social teaching networks.

\section{Opportunities to observe others and talk about teaching}

Teachers identified the opportunity to watch other teachers teach as the induction activity that most assisted their professional learning: For me it's seeing teaching fleshed out. Being told something, getting something on paper, doesn't matter how good the presentation is, it's still not real. When you see a classroom in action you've got everything in front of you and you've got the contacts basically. You're seeing how things work in the classroom, how the children respond ... it's probably the feel factor that you get. You get a feel for what's happening whereas you don't get that when you're just sort of taught it or told it. (David, 31-40, primary)
Beginning teachers also valued the formative feedback provided by their colleagues following formal observations. None of our teachers expressed any anxiety about their tutor teacher providing both formative and summative assessment of their teaching, although one teacher reported that he had actively sought out the "hard" feedback that he thought his mentor might not provide for fear of harming the mentoring relationship:

I really enjoy people coming into my classroom. A lot of people hate it but in my first year I had my principal come in and watch me teach and everyone else was [saying] 'What did you do that for?' It was so I could get some good feedback because I knew he would be quite honest. He didn't have to deal with me day to day and be my mentor and stuff like that so he could be quite honest if he thought there were areas I needed to work on because he didn't have to feel like he would hurt my feelings as much as maybe my tutor teacher who worked with me every day. (Robert, 26-30, intermediate)

\section{Wider networking opportunities}

Opportunities to participate in networks both inside and outside the school have been identified as being important for teacher induction. Beginning teacher support groups were appreciated when they were relevant to beginning teacher needs. The opportunities to reconnect with peers from initial teacher education and to meet other teachers were perceived as the most valuable aspects of these groups, in addition to the professional learning that the advisers had planned.

A few secondary teachers had been encouraged to join their professional subject associations although they tended to prioritise their current responsibilities rather than risk spending time on activities with uncertain outcomes:

Jack: Actually we did go on a scholarship training day earlier on this year at the college of education which was very useful. A lot of good strategies came out of that also just sitting around with a lot of very experienced teachers, English teachers, and sort of hearing what they did and how they've done it and stuff like that, was very, very useful.

Interviewer: Are you part of the English Teachers Association?

Jack: No. I should be by the sounds [of it]. (Jack, 31-40, secondary) 
This suggests that new teachers should be actively encouraged to look outside their schools to participate in wider professional networks. Opportunities to work on teaching-related tasks with teachers from other schools were also perceived to strengthen beginning teachers' pedagogical content knowledge. Beginning secondary teachers reported little engagement in external development to enhance their content and pedagogical content knowledge, which meant that their professional learning was extremely dependent on the quality of what was offered within their schools.

The opportunities for school-based, curriculum-focused professional learning differed according to sector group. Primary teachers identified school-based professional development contracts with an emphasis on collective planning and assessment as contributing to improvements in their confidence and teaching approaches. Many of these contracts were perceived to collectively build teachers' content and pedagogical knowledge, thus facilitating school-wide understandings and approaches. Our teachers' satisfaction was heightened because student progress and achievement became more visible to them. Secondary teachers did not appear to have access to similar learning opportunities apart from working with colleagues on NCEA ${ }^{2}$ curriculum and assessment. Teachers also valued opportunities to choose professional development activities that addressed their personal learning interests, but ultimately influenced their teaching.

\section{Conclusion}

Particular induction practices which mattered for teachers in our study relied on what principals and other teachers did at the school level. It was school-level practices which served to keep the teachers in their schools rather than national-level policy which provided funding for schools to provide induction programmes. For example, it mattered whether principals had systems in place to ensure time for quality supervision and gave consideration to the nature of the teaching assignment. Care was needed with timetables to make it possible for the beginning teachers to have regular interactions with a range of colleagues (not just the assigned mentor) who displayed a commitment to improving their own and others' teaching. When beginning teachers were inducted into such collegial cultures they were less likely to leave their schools, and almost without exception they reported satisfaction with their decisions to become teachers, deriving personal and professional fulfilment from that sense of belonging to a vibrant learning community. Many of these teachers, now in their fifth year of teaching, want to play a part in supporting the learning of other new teachers to ensure that they are even better supported. Sadly, only a small number have had additional professional development to equip them for these roles. Somewhat disturbingly, some of the teachers in our study who were in less supportive schools and had been left alone to figure out how to teach were now mentoring their new colleagues, without the benefit of professional development to assist them to do this work well.

The challenge is to increase the quality of induction for all beginning teachers regardless of their sector affiliation.

The teachers in our study started out as showing early promise as teachers and as likely to make a valuable contribution to their profession. Not all of them have worked in schools that have allowed this potential to be realised. Some have changed schools several times, searching for a school that provides a context where they are able to teach well. Others have left the school sector altogether, while others are investing more of their energies into nonclassroom activities. The importance of a systematic and high-quality approach within schools to the specific learning needs of new teachers is becoming increasingly evident, and ongoing research such as the New Zealand Teachers Council's Learning to Teach research programme $e^{3}$ is reinforcing that induction funding should be used in ways that give all of our new teachers the best possible start in their careers. More strategic use of the funding could include better professional learning opportunities and support for tutor teachers so that they are able to provide the targeted mentoring that will contribute to new teachers who love their work, who thrive on the challenges that teaching provides, and who continue to "make a difference" to those whom they teach and to the teaching profession.

\section{Notes}

1 The PRT time allowance is 0.2 in the first year of teaching, and 0.1 in the second year.

2 National Certificate of Educational Achievement, a three-level standards-based qualification for students in Years 11, 12, and 13.

3 The research reports are available on the Teachers Council website at: www. teacherscouncil.govt.nz/communication/ publications/research.stm

\section{References}

Bubb, S. (2007, September). The impact of induction on newly qualified teachers in England. Paper presented at BERA conference, London.

Bubb, S., Earley, P., \& Totterdell, M. (2005). Accountability and responsibility: "Rogue" school leaders and the induction of new teachers in England. Oxford Review of Education, 31(2), 255-272.

Cameron, M., Baker, R., \& Lovett, S. (2006). Teachers of promise: Getting started in teaching. Wellington: New Zealand Council for Educational Research.

Cameron, M., Berger, J. G., Lovett, S., \& Baker, R. (2007, April). "Ako": Being a teacher, being a learner, being part of a learning profession. Paper presented at the American Educational Research Association annual conference, Chicago. Available at http://www.nzcer.org. nz

Cochran-Smith, M. (2004). Stayers, leavers, lovers and dreamers: Insights about teacher retention. Journal of Teacher Education, 55(5), 387-393 (Editorial).

Dewar, S., Kennedy, S., Staig, C., \& Cox, L. (2003). Recruitment and retention in New Zealand secondary schools. Information from a series of interviews, with a focus on beginning teachers, returning teachers, and heads of departments. Wellington: Ministry of Education.

Elvidge, C. (2002). Teacher supply: Beginning teacher characteristics and mobility. Wellington: Demographics and Statistical Analysis Unit, Ministry of Education.

Feiman-Nemser, S. (2001). From preparation to practice: Designing a continuum to strengthen and sustain teaching. Teachers College Record, 10(6), 1013-1055.

Hargreaves, A., \& Fullan, M. (2000). Mentoring in the new millennium. Theory Into Practice, $39,50-56$.

Ingersoll, R. M., \& Kralik, J. M. (2004). The impact of mentoring on teacher retention: What the research says. Denver, CO: Education Commission of the States.

Johnson, S. M., Kardos, S. M., Kauffman, D., Liu, E., \& Donaldson, M. L. (2004). The support gap: New teachers' experiences in high income and low income schools. Retrieved 12 December 2005, from http://www.epaa.asu. edu/epaa/v12n61/

Kelley, L. M. (2004). Why induction matters. Journal of Teacher Education, 55, 438-448. 
Mansell, R. (1996, December). Professional development of beginning teachers: How does it work? Paper presented at the New Zealand Association for Research in Education conference, Nelson, New Zealand.

Mulford, B. (2003). The role of school leadership in attracting and retaining teachers and promoting innovative schools and students. Commissioned paper by the Review of Teaching and Teacher Education. Canberra: Department of Education, Science and Training. Retrieved 9 May 2006, from http://www.dest.gov. au/sectors/school_education/publications_ resources/profiles/school_leadership.htm

OECD. (2005). Teachers matter: Attracting, developing and retaining effective teachers. Paris: Author.

Renwick, M. (2001). Support for beginning teachers. Wellington: Ministry of Education. Roehrig, A. D., Pressley, M., \& Talotta, D. A. (2002). Stories of beginning teachers. Firstyear challenges and beyond. Notre Dame, IN: University of Notre Dame.
Scott, C., \& Dinham, S. (2003). The development of scales to measure teacher and school executive occupational satisfaction. The Journal of Educational Administration, 41(1), 74-86.

Stansbury, K., \& Zimmerman, J. (2000). Lifelines to the classroom: Designing support for beginning teachers. San Francisco, CA: WestEd.

Stansbury, K., \& Zimmerman, J. (2002). Smart induction programs become lifelines for the beginning teacher. Journal of Staff Development, 23(4), 10-17.
Street, C. (2004). Examining learning through a cultural lens: How mentors guide newcomers into a professional community of learners. Teacher Education Quarterly, 31(2), 7-24.

Vonk, J. H. C. (1994). Teacher induction: The great omission in education. In B. Moon (Ed.), Handbook of teacher training in Europe (pp. 85-109). London: David Fulton.

Youngs, P. (2002). State and district policy related to mentoring and new teacher induction in Connecticut. New York: National Commission on Teaching and America's Future.

Marie Cameron is project leader for the Teachers of Promise research project at the New Zealand Council for Educational Research.

Email: mariecœxtra.co.nz

Susan Lovett is co-ordinator of the Master of Teaching and Learning Degree, School of Educational Studies and Human Development at the University of Canterbury College of Education.

Email: Susan.Lovettœcanterbury.ac.nz

Jennifer Garvey Berger is a senior researcher at the New Zealand Council for Educational Research.

Email: jbergerıøgmu.edu

\section{Pricing structure for set}

\section{Multiple subscriptions are now affordable! First subscription-\$65.00 Additional subscriptions (print) only $\$ 35.00$ each!*}

*Note: These prices apply to New Zealand subscriptions only.

\section{And ... for print subscribers only}

\section{set on CD!!}

\section{Makes professional development easy!}

If you subscribe to set (print) you can also buy the electronic version on CD ROM (3 CDs per year).

PRICE: NZ subscribers

Schools: $\$ 50.00$ (includes GST and p\&p) Tertiary institutions: $\$ 250.00$ (includes GST and p\&p) NOTE: The purchase of set on CD permits the use of the CD on a single-site network or on an unlimited number of computers on a single site.

Other NZ institutions/organisations and overseas subscribers: price by negotiation. 